to hospital were relatively short and use of the equipment was low; had each health centre seen 12 patients a week and the patients lived an average of 40 $\mathrm{km}$ from the hospital, teledermatology would have been as cheap. Other factors, such as cheaper equipment, would also improve the relative economics for telemedicine. Nevertheless it is clear that, although real time teledermatology is both clinically effective and economic in the appropriate circumstances, it is not likely to be useful in large cities, except possibly for secondary-to-tertiary consulting or for educational use. Its place in the overall management of dermatology patients from primary care, and indeed the place of pre-recorded teledermatology ("store-andforward") remains to be established in future trials.

Contributors: RW defined the research question, contributed to the conception and design of the trial, analysed the data, cowrote the paper, and is the guarantor. MAL contributed to the conception and design of the trial, coordinated the trial centres, analysed the data, and cowrote the paper. RC, DJE, KS, CM, NV, JP, SEB, and HEL contributed to the conception and design of the trial and helped write the paper.

Funding: The UK multicentre teledermatology trial was funded by the NHS research and development programme (primary and secondary interface). We also received support from Southern Health and Social Services Board (Northern Ireland), Glaxo, and Steifel. Segal Quince Wicksteed consultancy provided health economics advice.

Competing interests: None declared.
1 House of Commons Official Report (Hansard) 1998 October 5;593 (201):cols 68-9.

2 Royal College of General Practitioners. Morbidity statistics from general practice. Fourth national study 1991-92. London: HMSO, 1995.

3 Department of Health. Personnel and social services statistics for England. London: HMSO, 1994.

4 Ryan T. Dermatology - a service under threat. London: British Association of Dermatology, 1993.

5 Oakley AMM, Astwood DR, Loane M, Duffill MB, Rademaker M, Wootton R. Diagnostic accuracy of teledermatology: results of a preliminary study in New Zealand. N Z Med J 1997;110:51-3.

6 Gilmour E, Campbell SM, Loane MA, Esmail A, Griffiths CEM, Roland MO, et al. Comparison of teleconsultations and face-to-face consultations: preliminary results of a UK multicentre teledermatology study. $\mathrm{Br} \mathrm{J}$ Dermatol 1998:139:81-7.

7 Loane M, Corbett R, Bloomer S, Eedy D, Gore H, Mathews C, et al. Diagnostic accuracy and clinical management by real-time teledermatology: results from the Northern Ireland arms of the UK multicentre teledermatology trial. J Telemedicine Telecare 1998;4:95-100.

8 Phillips CM, Burke WA, Shechter A, Stone D, Balch D, Gustke S. Reliability of dermatology teleconsultations with the use of teleconferencing technology. J Am Acad Dermatol 1997:37:398-402.

9 Lesher JL, Davis LS, Gourdin FW, English D, Thompson WO. Telemedicine evaluation of cutaneous diseases: a blinded comparative study. J Am Acad Dermatol 1998;38:27-31.

10 Lowitt MH, Kessler II, Kauffman L, Hooper FJ, Siegel E, Burnett JW. Teledermatology and in-person examinations. Arch Dermatol 1998;134:471-6.

11 Loane MA, Bloomer SE, Corbett R, Eedy DJ, Gore HE, Mathews C, et al. Patient satisfaction with real-time teledermatology in Northern Ireland. $J$ Telemedicine Telecare 1998;4:36-40.

12 Loane MA, Bloomer SE, Corbett R, Eedy DJ, Gore HE, Hicks N, et al. Patient cost-benefit analysis of teledermatology measured in a randomized control trial. J Telemedicine Telecare 1999;5(suppl 1):1-3.

13 Altman DG. Practical statistics for medical research. London: Chapman and Hall, 1991.

14 Vierhout WP, Knottnerus JA, van Ooij A, Crebolder HF, Pop P, Wesselingh-Megens AM, et al. Effectiveness of joint consultation sessions of general practitioners and orthopaedic surgeons for locomotor-system disorders. Lancet 1995;346:990-4.

(Accepted 3 February 2000)

\title{
INFOPOINTS
}

\section{Online appointment booking to rapid access chest pain clinic}

The English National Service Framework for Coronary Heart Disease recommends rapid access chest pain clinics for the prompt management of angina. ${ }^{1}$ Moreover, consultations in general practitioners' surgeries should be "structured and guided by the active use of a paper or electronic practice protocol/guideline which includes the indications and arrangements for accessing ... specialist advice [and] exercise testing."

We have implemented a service that provides early, protocol driven access to exercise testing and consultation with a cardiologist. The generic methodology used could be translated without difficulty to other specialties. The service had the following design goals:

- To use web browsers via the NHSNet

- To use the hospital's web server

- To obtain a patient's history

- To use this to determine the need for referral

- To allow flexible booking of appointments with immediate confirmation

- To integrate with local hospital databases

- To allow online entering of exercise test results

- To calculate a patient's risk of coronary heart disease from the general practitioner's data and the exercise test results

- To provide a report with the patient's management plan

- To incur no additional costs for the general practitioners

Since the launch of the service at the Royal Alexandra Hospital in December 1999, 15 general practitioners have referred 100 patients. The median time for clinic attendance has been three days (range 2-14 days), with $88 \%$ of patients seen within a week.

This service represents one of the first web based implementations of a complete protocol-driven booking, analysis, and reporting system. Comments from general practitioners have been positive and appreciative of the rapid response. They have suggested that integrating the system into their computer system would increase its usefulness. This should be achieved in the near future as part of the NHSiS-Scottish Care Information initiative.

Iain Findlay consultant cardiologist iain.findlay@rah.scot.nhs.uk

Janey Sommerville database developer

Paul MacIntyre consultant cardiologist

Royal Alexandra Hospital, Paisley

Allan Harkness research fellow in cardiology

David Cunningham clinical database manager,

MRC Clinical Research Initiative in Heart Failure,

University of Glasgow, Glasgow

Barry Goldberg director, Centre for Health Informatics,

University of Wales, Swansea

Funding: The Centre for Health Informatics is supported by an educational grant from MSD Pharmaceuticals. Competing interests: None declared.

1 Department of Health. National service framework for coronary heart disease. London: DoH, 2000. (www.doh.gov.uk/nsf/coronary.htm\# chdnsf)

Rapid access chest pain service http://www.carenet-project.co.uk/racps 